\title{
Small-scale spatial genetic structure in Scopalina lophyropoda, an encrusting sponge with philopatric larval dispersal and frequent fission and fusion events
}

\author{
Andrea Blanquer ${ }^{1, *}$, María-J. Uriz $^{1}$, Juli Caujapé-Castells ${ }^{2}$ \\ ${ }^{1}$ Centre d'Estudis Avançats de Blanes-CSIC, accés cala St Francesc 14, 17300 Blanes, Girona, Spain \\ ${ }^{2}$ Departamento de Biodiversidad Molecular y Banco de ADN, Jardín Botánico Canario ‘Viera y Clavijo', Ap. de Correos 14, \\ Tafira Alta, 35017 Las Palmas de Gran Canaria, Spain
}

\begin{abstract}
Insight from the spatial genetic structure (SGS) of a species is fundamental to understanding the patterns of effective dispersal and gene flow among its populations. Despite the ecological importance of sponges and the variety of reproduction and dispersal strategies they present, which can strongly influence SGS, there is only 1 study assessing small-scale SGS in sponges. That species had a continuous distribution and relatively wide-scale larval dispersal. Here we study the contribution of sexual and asexual reproduction, and the breeding and mating system to the SGS of a sponge species, Scopalina lophyropoda, with a patchy distribution and more limited larval dispersal. All individuals from 3 populations were mapped and genetically characterised for 7 microsatellite loci. The extent of clonality was minor (ca. $7 \%$ ), possibly caused by a balance between fissions and fusions. The scarce clonality did not contribute to the SGS, which was analysed by autocorrelation statistics at both the ramet (including clones) and the genet (excluding clones) levels. The spatial autocorrelation analyses elicited a pattern of strong SGS at the small scale, confirming the predictions of philopatric larval dispersal, which fosters isolation by distance. All these patterns, however, contrast with the conspicuous lack of inbreeding detected in the populations, which is in agreement with recent data on other marine modular invertebrates and confirms that strong SGS does not necessarily imply inbreeding.
\end{abstract}

KEY WORDS: Clones $\cdot$ Kinship coefficients $\cdot$ Moran's I $\cdot$ Porifera $\cdot$ Spatial distribution

\section{INTRODUCTION}

Spatial genetic structure (SGS, i.e. the non-random spatial distribution of genotypes) is strongly influenced by several reproduction traits such as mating system, inbreeding, clonality, and individual fitness (Epperson 1993). Molecular data have been used for the study of small-scale SGS of various groups of marine modular invertebrates (i.e. corals, bryozoans and ascidians) by using autocorrelation statistics (e.g. McFadden \& Aydin 1996, Miller 1998, Pemberton et al. 2007, Miller \& Ayre 2008). Although sponges are common compo- nents of marine systems (e.g. Vacelet 1979), and have life-history traits that might lead to a high level of spatial genetic structure (e.g. Uriz et al. 1998), only 1 study to date addresses sponge genetic structure at small spatial scales (Calderon et al. 2007).

Sponges display a variety of reproduction and dispersal strategies, which can influence population SGS. They reproduce sexually by releasing sperm, eggs and larvae and can also combine sexual and asexual reproduction, mainly through budding and fragmentation (e.g. Wulff 1991, Turon et al. 1998). The scarce studies available on larval behaviour suggest limited dispersal 
(e.g. Uriz et al. 1998, Mariani et al. 2006) but the extent of sponge sperm dispersal is unknown. Graft acceptance and rejection experiments indicate that clonality may be important in shaping the genetic structure of a sponge population (see Boury-Esnault \& Solé-Cava 2003 for review). Asexually produced propagules appear to have higher survival rates than settlers resulting from larvae since the former circumvent the post-settlement period, when settler vulnerability is the highest (Hunt \& Scheibling 1997).

The only sponge study focusing on SGS at short distances (from $\mathrm{cm}$ to $\mathrm{m}$ ) dealt with a Mediterranean encrusting species Crambe crambe with continuous distribution and relatively high larval dispersal (Calderon et al. 2007). The present study focuses on another encrusting sponge: Scopalina lophyropoda (Schmidt), which has an aggregated distribution (Blanquer 2007) and philopatric larval behaviour (Uriz et al. 1998, Mariani et al. 2006).

The extremely patchy distribution of Scopalina lophyropoda and its larval philopatry advocate high levels of inbreeding. On the other hand, the observed fission events (Maldonado \& Uriz 1999, Blanquer et al. 2008) would promote clonality. All these features (clonality, patchiness, philopatry and inbreeding) allowed us to predict strong small-scale SGS in this species. Thus, the objectives of the present study were to verify or disprove our prediction by (1) inferring the intrapopulation SGS of the species by using microsatellite data and autocorrelation analyses, (2) assessing the extent of sexual and clonal reproduction and their respective contributions to the SGS, and (3) gaining insights on the breeding and mating structure of the species. The present study also aimed to broaden the knowledge of SGS of encrusting Mediterranean sponges at small scales by focusing on a second model species with an opposite distribution pattern to that of the previously studied species. Moreover, the results may provide baseline insights for further investigations on other patchily distributed modular benthic invertebrates.

\section{MATERIALS AND METHODS}

Study site and sampling design. Three populations of Scopalina lophyropoda from the NE littoral of the Iberian Peninsula (NW Mediterranean, 41 ${ }^{\circ} 40.12^{\prime} \mathrm{N}$, $\left.2^{\circ} 47.10^{\prime} \mathrm{E}\right)$ were studied. The study sites consist of north-facing rocky walls from 8 to $16 \mathrm{~m}$ in depth where $S$. lophyropoda is one of the dominant invertebrates in terms of surface cover (Uriz et al. 1998). The rocky walls are perpendicular to the sea surface, but parallel and separated by $25 \mathrm{~m}$ from one another (Fig. 1). They occur at increasing depths: 8 to $10 \mathrm{~m}$ (Wall 1), 12 to

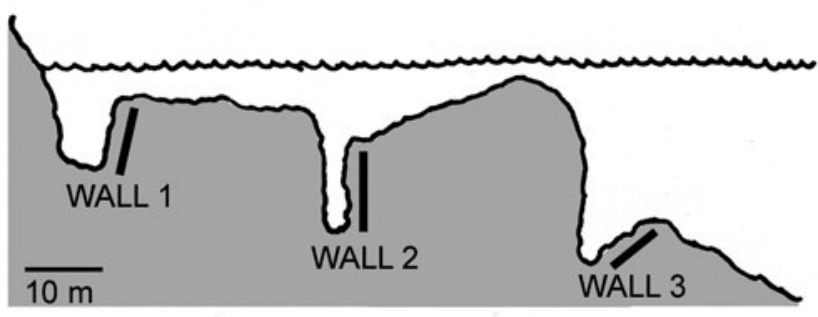

Fig. 1. Scopalina lophyropoda. Schematic representation of the location of the populations studied. Bathymetric profile of the sampling area with the location of the sampling walls

$14 \mathrm{~m}$ (Wall 2) and 14 to $16 \mathrm{~m}$ (Wall 3) and extend for $>100 \mathrm{~m}$ horizontally.

Since populations were relatively small and spatial autocorrelation has been reported to strongly depend on the scale and intensity of sampling (Hämmerli \& Reusch 2003), we collected sponge fragments from all the individuals along each rocky wall $(\mathrm{n}=27, \mathrm{n}=13$ and $\mathrm{n}=30$ for Walls 1,2 and 3, respectively). There were no individuals in the rocky areas between walls.

In order to determine the distance between any pair of individuals, 1 individual at the middle of each wall was taken as a reference. The distance (in $\mathrm{cm}$ ) and angle (in degrees) of all other sampled individuals relative to the reference sponge were measured and subsequently, distances between the centres of all individuals were calculated using the cosine theorem. The samples, consisting of small fragments of the sponges, were preserved in ethanol, carefully cleaned of foreign tissues under a binocular microscope, and stored at $-20^{\circ} \mathrm{C}$ until DNA extraction.

Microsatellite genotyping. Hypervariable molecular markers such as microsatellites allow differentiation between sexually and clonally originated individuals of the same species and thus are a proper choice for assessing within-population genetic structures (Reusch et al. 2000).

Allelic variation at 7 microsatellite loci (Scol_c, Scol_d, Scol_i, Scol_l,Scol_n, Scol_p and Scol_r) previously isolated from a genomic library of Scopalina lophyropoda (Blanquer et al. 2005) was assessed. Total DNA was extracted as in Pascual et al. (1997) and microsatellites were sized following the conditions described in Blanquer et al. (2005). As is common practice, 2 independent readers checked the results to avoid scoring errors.

Clone identification. The probability that 2 distinct sexual reproduction events could produce individuals sharing identical multilocus genotypes (MLGs) was estimated using the program MLGsim (10 000 simulations; Stenberg et al. 2003).

Due to a lack of specific terminology for animal modular species, we adopted the terms 'ramet' (for each mod- 
ular unit from asexual reproduction) and 'genet' (for each genotype from sexual reproduction) that were originally developed for clonal plants (Harper 1977).

Population genetic analyses. Several indices were used to estimate genetic diversity for the pooled walls and for each wall separately, to check whether their topology could influence effective dispersal. The analyses within populations were all performed at the genet level. Detected clones were removed for the population analyses, since clonality could strongly bias the results. Observed (A) and effective (Ae) number of alleles per locus (as in Kimura \& Crow 1964), allele frequencies, expected and observed heterozygosities $\left(H_{\mathrm{e}}\right.$ and $H_{\mathrm{o}}$, respectively), Ewens-Watterson tests of neutrality (1000 simulated samples) and departures from HardyWeinberg equilibrium (HW) were estimated using POPGENE (Yeh et al. 1997); linkage disequilibrium for all pairs of loci was tested using GENEPOP (Raymound \& Rousset 1995), and inbreeding coefficients ( $F_{\text {ISi }}$ Weir \& Cockerham 1984) were calculated using FSTAT (Goudet 1995). In order to quantify differentiation between walls, we estimated $F_{\mathrm{ST}}$ (Weir \& Cockerham 1984) using ARLEQUIN (Schneider et al. 2000). The computer program TRANSFORMER-3 (Caujapé-Castells \& Baccarani-Rosas 2005) was used to generate all the input files needed to analyse these data.

Spatial autocorrelation analyses. Spatial autocorrelation tests the within-population genetic relatedness of individuals as a function of their relative position in space. It is considered the best methodology to quantify the genetic structure caused by limited dispersal at small scales, within the population level (Epperson \& Li 1996). We used the relationship coefficient Moran's I (MI; Moran 1948) and the kinship coefficient $\varphi_{\mathrm{ij}}$ (Loiselle et al. 1995) as spatial autocorrelation statistics. MI ranges from -1 to +1 . Positive values of MI indicate positive spatial autocorrelation, which means that individuals that are genetically closer also tend to be closer in space. By contrast, negative values of MI indicate negative spatial autocorrelation, which means that genetically closer individuals tend to be separated in space. Kinship coefficients such as $\varphi_{\mathrm{ij}}$ are considered to be analogous to relationship coefficients such as MI (Hardy \& Vekemans 1999). However, unlike $\varphi_{\mathrm{ij}}$, MI appears to depend only on dispersal and not on the rate of selfing (Epperson 2005).

Autocorrelation analyses were performed with SPAGeDI software (Hardy \& Vekemans 2002), and the correlograms were plotted using 5 distance classes for all the analyses, given the limited population sizes and the reduced sampling distances. The boundaries of the distance classes were chosen so that each one included a similar number of pairs of individuals in order not to influence statistical power. The $95 \%$ CIs were included in the plots. The analyses were performed at the ramet level and repeated at the genet level whenever identical MLGs were detected, since clonality is expected to generate strong spatial autocorrelation in the genotype distribution (Reusch et al. 1999). Only 1 of the clones was included in the genet-level analysis. The physical distance from this individual to any other was calculated as the average value of the distances of all those individuals sharing the MLG.

\section{RESULTS}

\section{Genotypic diversity}

All individuals were successfully genotyped for all the microsatellite loci. Over $90 \%$ of MLGs were presented by a single individual. Shared MLGs (Table 1) were only found in Wall 1 (1 group of 4 individuals, 2 groups of 3 individuals and 1 group of 2 individuals). Individuals sharing MLG were located within $0.45 \mathrm{~m}$ of each other. The probability of finding each specific MLG with random sexual mating was significantly low ( $p<0.05$ ) only for MLG 1 (4 individuals) and MLG 4 (3 individuals; Table 1). Thus, only ramets from those 2 MLGs were considered as resulting from clonal reproduction (i.e. 5 out of 70 individuals; Table 1).

\section{Mating system}

Multilocus $F_{\mathrm{ST}}$ values were 0.019 between Walls 1 and 2, 0.023 between Walls 1 and 3, and 0.012 between Walls 2 and 3 . All $F_{\text {ST }}$ values, except between Walls 2 and 3, were statistically significant at an alpha level of 0.05. The low number of individuals in Wall $2(n=13)$ probably brought about a low power of the test. How-

Table 1. Scopalina lophyropoda. Identical multilocus genotypes (MLGs) detected in the populations surveyed. Genotypes per locus are designed using the allele sizes (bold numbers indicate the allele with the highest frequency in the population); $N$, number of individuals sharing $\mathrm{MLG}_{i}{ }^{*}$ significantly (at $\mathrm{p}<0.05$ ) small probability of being result of random mating, and ns, not significant according to MLGsim software

\begin{tabular}{|c|c|c|c|c|c|c|c|c|c|}
\hline \multirow{2}{*}{ MLG } & & & & \multicolumn{4}{|l|}{ Genotype } & \multirow{2}{*}{$\mathrm{N}$} & \multirow{2}{*}{ MLGsim } \\
\hline & Scol_i & Scol_c & Scol_d & Scol_l & Scol_n & Scol_p & Scol_r & & \\
\hline MLG1 & $153 / 153$ & $146 / \mathbf{1 4 8}$ & $319 / 319$ & $169 / 169$ & $193 / 215$ & $149 / 149$ & $124 / 124$ & 4 & * \\
\hline MLG2 & $153 / 153$ & $148 / 148$ & $319 / 319$ & 169/171 & $193 / 215$ & $149 / 149$ & $124 / 124$ & 3 & $\mathrm{~ns}$ \\
\hline MLG3 & $153 / 153$ & $146 / \mathbf{1 4 8}$ & $315 / 317$ & 169/171 & $199 / 215$ & $149 / 149$ & $124 / 124$ & 2 & $\mathrm{~ns}$ \\
\hline MLG4 & $153 / 153$ & $146 / 146$ & $317 / 317$ & $169 / 169$ & $193 / 193$ & $149 / 149$ & $124 / 124$ & 3 & ${ }^{*}$ \\
\hline
\end{tabular}


ever, considering these values, that there were private alleles in all walls, and that all the individuals were sampled, each wall was considered as independent for posterior analyses.

Only a few departures from HW equilibrium were detected, involving 4 different loci: 3 heterozygote excesses (Scol_c in all walls, and Scol_d and Scol_r in Wall 2) and 1 heterozygote deficit (Scol_n in Wall 2, p < 0.001, Markov chain method; Table 2). Multilocus fixation indices $\left(F_{\mathrm{IS}}\right)$ were $-0.075,-0.036$ and -0.173 for Walls 1, 2 and 3, respectively (Table 2). Only the multilocus value for Wall 3 was significantly different from 0 (i.e. random mating). Per locus, most of the inbreeding coefficient values (18 out of 21 ) were negative, although only 5 of them were significant (Table 2). However, there was 1 significant positive $F_{\text {IS }}$ value for Scol_n in Wall 2 (0.696). All loci behaved as neutral according to the Ewens-Watterson test for neutrality.

Table 2. Scopalina lophyropoda. Genetic polymorphism descriptors for each of the 3 walls and for the total population. Total alleles (double sample size, TA), observed number of different alleles per site $(\mathrm{A})$, observed heterozygosity $\left(H_{0}\right)$, expected heterozygosity $\left(H_{\mathrm{e}}\right)$, inbreeding coefficients $\left(F_{\mathrm{IS}}\right.$; ${ }^{*} \mathrm{p}<0.05$ ) and departure from Hardy-Weinberg equilibrium (HWE; ns, not significant; ${ }^{*} \mathrm{p}<0.05 ;{ }^{* *} \mathrm{p}<0.001$ )

\begin{tabular}{|c|c|c|c|c|c|c|}
\hline Loci & TA & $\mathrm{A}$ & $H_{\mathrm{o}}$ & $H_{\mathrm{e}}$ & $F_{\mathrm{IS}}$ & HWE \\
\hline \multicolumn{7}{|l|}{ Wall 1} \\
\hline Scol_i & 44 & 2 & 0.045 & 0.045 & -0.010 & ns \\
\hline Scol_c & 44 & 4 & 0.591 & 0.470 & $-0.264^{*}$ & ${ }^{*}$ \\
\hline Scol_d & 44 & 5 & 0.682 & 0.685 & 0.005 & ns \\
\hline Scol_l & 44 & 4 & 0.591 & 0.568 & -0.042 & ns \\
\hline Scol_n & 44 & 3 & 0.591 & 0.576 & -0.026 & $\mathrm{~ns}$ \\
\hline Scol_p & 44 & 2 & 0.046 & 0.046 & -0.010 & $\mathrm{~ns}$ \\
\hline Scol_r & 44 & 5 & 0.409 & 0.364 & -0.128 & $\mathrm{~ns}$ \\
\hline \multicolumn{2}{|c|}{ Average } & 3.6 & 0.422 & 0.363 & & \\
\hline Multiloc & & & & & -0.075 & \\
\hline \multicolumn{7}{|c|}{ Wall 2} \\
\hline Scol_i & 26 & 2 & 0.154 & 0.148 & -0.043 & ns \\
\hline Scol_c & 26 & 4 & 0.767 & 0.545 & $-0.437^{*}$ & ${ }^{*}$ \\
\hline Scol_d & 26 & 4 & 0.846 & 0.717 & $-0.189^{*}$ & ${ }^{*}$ \\
\hline Scol_1 & 26 & 2 & 0.461 & 0.492 & 0.065 & ns \\
\hline Scol_n & 26 & 3 & 0.154 & 0.492 & $0.696^{*}$ & ${ }^{* *}$ \\
\hline Scol_p & 26 & 2 & 0.077 & 0.077 & -0.010 & ns \\
\hline Scol_r & 26 & 4 & 0.615 & 0.505 & $-0.231^{*}$ & ${ }^{*}$ \\
\hline \multicolumn{2}{|c|}{ Average } & 3.0 & 0.440 & 0.425 & & \\
\hline Multiloc & & & & & -0.036 & \\
\hline \multicolumn{7}{|c|}{ Wall 3} \\
\hline Scol_i & 60 & 2 & 0.167 & 0.155 & -0.074 & $\mathrm{~ns}$ \\
\hline Scol_c & 60 & 3 & 0.867 & 0.586 & $-0.492^{*}$ & ${ }^{* *}$ \\
\hline Scol_d & 60 & 5 & 0.767 & 0.746 & -0.029 & ns \\
\hline Scol_1 & 60 & 8 & 0.667 & 0.595 & -0.190 & ns \\
\hline Scol_n & 60 & 4 & 0.600 & 0.559 & -0.075 & ns \\
\hline Scol_p & 60 & 4 & 0.333 & 0.299 & -0.118 & ns \\
\hline Scol_r & 60 & 4 & 0.433 & 0.370 & -0.174 & $\mathrm{~ns}$ \\
\hline \multicolumn{2}{|c|}{ Average } & 4.3 & 0.548 & 0.473 & & \\
\hline \multicolumn{2}{|c|}{ Multilocus } & & & & $-0.173^{*}$ & \\
\hline
\end{tabular}

Linkage disequilibrium tests were consistently nonsignificant for all pairs of loci across the walls.

\section{Spatial genetic structure}

The shape of the multilocus autocorrelograms (Fig. 2) for both $\varphi_{\mathrm{ij}}$ and MI were consistently similar for all walls, although $\varphi_{\mathrm{ij}}$ values were up to 10 -fold smaller than MI values. In Wall 1 (Fig. 2A), there were significantly positive $\varphi_{\mathrm{ij}}$ and MI values for the first distance class and significantly negative values for the second and third distance classes. Correlograms at the genet level were more conservative and only showed significant autocorrelation for the first distance class. In Wall 2 (Fig. 2B), multilocus MI values were significantly positive for the first distance class and significantly negative for the 3 last distance classes whereas the $\varphi_{\mathrm{ij}}$ values were not significant in any case. By contrast, MI and $\varphi_{\mathrm{ij}}$ correlograms displayed the same shape in Wall 3 (Fig. 2C), with nonsignificant negative values in all distance classes.

When pooling all individuals from the 3 walls, analyses with both MI and $\varphi_{\mathrm{ij}}$ showed a pattern of significant autocorrelation (Fig. 2D) with a more or less monotonic decline from significant positive values in the first distance class to significant negative values at the largest distance classes. Correlograms at the ramet and at the genet level for either statistic only varied slightly in the first distance class.

\section{DISCUSSION}

Microsatellites have proven to be useful markers to assess the SGS of very close populations of Scopalina lophyropoda. They allowed us to elucidate the breeding structure of its populations and confirmed, from a genetic perspective, the reported philopatric dispersal of its larvae (Uriz et al. 1998).

\section{Mating system}

Several marine modular invertebrates have been reported to show population inbreeding (e.g. Knowlton \& Jackson 1993, Le Goff-Vitry et al. 2004, GutierrezRodriguez \& Lasker 2004), which has been attributed to their potential self-fertilisation, and philopatric larval dispersal (Carlon 1999). Multilocus $F_{\mathrm{IS}}$ values based on microsatellites of the only other sponge studied so far (i.e. Crambe crambe; Duran et al. 2004) also revealed significant inbreeding in 9 out of 11 populations, which was attributed to a Wahlund effect induced by the existence of breeding units. The results 

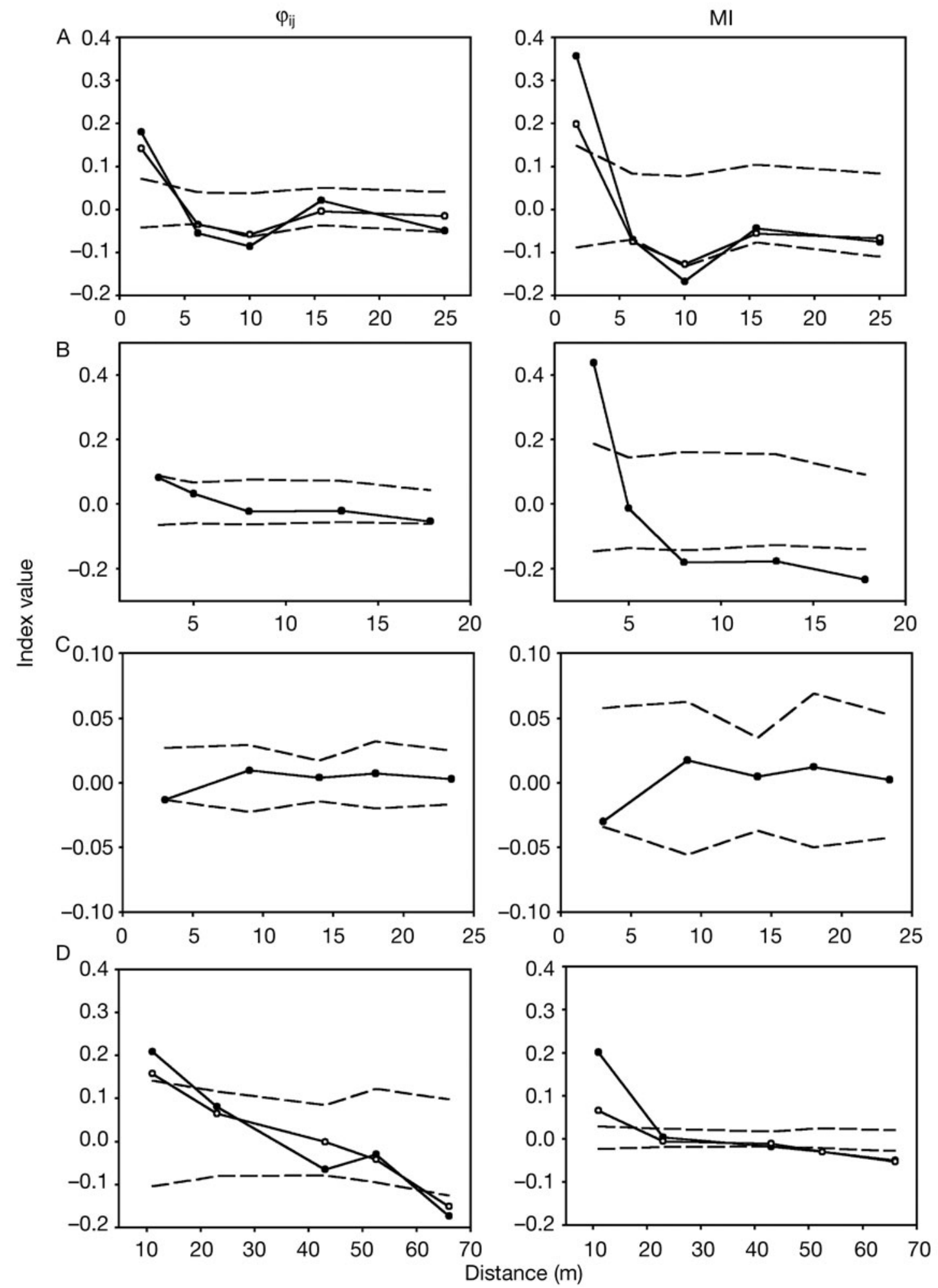

Fig. 2. Scopalina lophyropoda. Multilocus correlograms of MI (left) and $\varphi_{\mathrm{ij}}$ (right) values across 5 distance classes for the microsatellite data at different spatial levels. The $y$-axes represent the index value and $x$-axes the distance in meters. $\bullet$ represents the ramet and $O$ the genet analysis. (A) ramet and genet correlograms for Wall 1 population, (B) correlograms for Wall 2 population, (C) correlograms for Wall 3 population, (D) ramet and genet correlograms for the pooled populations. - - - give the 95\% CIs around the null hypotheses $\mathrm{MI}=0$ and $\varphi_{\mathrm{ij}}=0$ 
for $C$. crambe match what would be expected from the biological traits of many encrusting sponges. However, at odds with the bulk of the literature, and the species biological features, the negative multilocus $F_{\text {IS }}$ values found for Scopalina lophyropoda clearly indicate lack of inbreeding. A significant absence of inbreeding also occurs in other geographically distant populations of this species (Blanquer 2007), and consequently, outcrossing seems to be a general trait for $S$. lophyropoda at the several spatial scales analysed (ranging from $\mathrm{cm}$ to $100 \mathrm{~s}$ of $\mathrm{km}$ ).

However, the absence of inbreeding in this species with aggregated populations and short larval dispersal (Uriz et al. 1998, Mariani et al. 2006), although difficult to interpret, is in agreement with the conclusions of the several studies on other modular invertebrates, which report that restricted (both sexual and asexual) dispersal, strong population structure, and even consanguinity do not necessarily imply inbreeding depression (e.g. Grosberg 1987, Cohen 1990, Bishop \& Ryland 1993, Jones et al. 1994, McFadden 1997, Ayre \& Miller 2006). In fact, no satisfactory explanation about why inbreeding is so common in modular invertebrates has been found so far (Addison \& Hart 2005).

Random sperm dispersal may account for the random mating detected in the populations. Unfortunately, no data are available on sponge sperm dispersal, although some studies suggest that longevity of marine invertebrate sperm is larger than previously thought and thus the sperm has more opportunities to be dispersed (Johnson \& Yund 2004).

Other causes besides sperm dispersal may help the species to avoid inbreeding. First, the individuals might be genetic chimeras, (Boury-Esnault \& SoléCava 2003), which would be consistent with the heterozygosity excess detected. However, fusion between larvae from different individuals has been discarded as a potential cause (Maldonado \& Uriz 1999), and we did not find individuals with $>2$ alleles, although this does not mean that they do not exist. Second, a selfincompatibility system in the species or a selection favouring assortive mating might be also acting.

\section{Spatial population structure}

$F_{\mathrm{ST}}$ values, and the presence of private alleles in each wall, indicate that the 3 walls studied harboured genetically differentiated populations despite their proximity. The structure descriptors together with negative autocorrelation at the larger distance classes show that the walls represent physical barriers to larval dispersal, which reduces gene flow among walls.

Spatial autocorrelation analysis is indicated for quantifying the component of genetic structure due to limited dispersal (Hämmerli \& Reusch 2003). Our predictions on restricted dispersal in the species, based on its presumed philopatric larval behaviour (Uriz et al. 1998, Mariani et al. 2006), have been confirmed by autocorrelation statistics (Fig. 2), which detected the formation of pedigree structures. In contrast, clonality, which often contributes to the strong SGS at very small scales (Pemberton et al. 2007, Miller \& Ayre 2008), was irrelevant in Scopalina lophyropoda, since both the genet and the ramet analyses gave similar results.

The strong SGS found in Walls 1 and 2 is best explained by the isolation-by-distance model, whereby geographically closer individuals also bear a tight genetic relationship. In contrast, the particular topology of Wall 3 may have brought about a more complex pattern of water currents, and an increase gamete and larval dispersal fostering a random spatial distribution of the genotypes, which could explain the negative autocorrelation values. Similar patterns of variable autocorrelation between sites, related to area topology, were also found in corals (Miller 1998).

\section{Sexual vs. asexual reproduction}

The few studies available on the extent of asexual reproduction in sponges have mostly used allozyme markers, and report contrasting conclusions depending on the species. However, differences in the enzymes and methodologies used could well account for the divergent results. While sexual reproduction appeared to be the major contributor to local recruitment in populations of some sponge species (e.g. Duran et al. 2004, Whalan et al. 2005), asexual reproduction seemed to contribute to a variable extent to the maintenance of populations in other species (e.g. Miller et al. 2001, Zilberberg et al. 2006).

The low impact of clonality detected in Scopalina lophyropoda (only $7 \%$ of the individuals analysed may have had an asexual origin) is difficult to understand, considering the fission events recorded in adults (e.g. Maldonado \& Uriz 1999, Blanquer et al. 2008). However, in thin encrusting species such as $S$. lophyropoda, the clones resulting from fission remain attached to the substrate and thus close in space, which favours posterior fusions (Blanquer et al. 2008).

Summarising, the autocorrelation analysis with polymorphic molecular markers allowed us to assess the contribution of the mating system to the SGS at a small scale in Scopalina lophyropoda, and could be applied to other sponge species. The low incidence of clonality in our species suggests a balancing mechanism between fissions and fusions, which are also numerous (Blanquer et al. 2008). This balancing mechanism had not been reported so far in sponges, but makes sense 
from an ecological perspective, since it would allow the sponge to recover after partial mortality (Hughes \& Jackson 1980) and to encompass temporal competition with fast-growing organisms in seasonal seas such as the Mediterranean (Blanquer et al. 2008). The prediction that restricted larval dispersal in S. lophyropoda fosters isolation by distance, and promotes family clusters of individuals has been confirmed by the overall genetic structuring detected at a small spatial scale. Furthermore, the present study highlights the disagreement between biological traits, which suggested inbreeding in the populations, and genetic data. Sperm dispersal may account for the outcrossing detected. Experimental studies should take the present results as a background to investigate other causes (e.g. chimerism and/or a self-incompatibility system) for the enhanced outcrossing capabilities of S. lophyropoda.

Acknowledgements. We are grateful to M. Pascual for the laboratory facilities at the Genetic Department of the University of Barcelona and to X. Turon for his advice. This study was funded by grant CTM2007-66635-CO2 from the Spanish Government to M.J.U. and an I3P fellowship to A.B.

\section{LITERATURE CITED}

Addison JA, Hart MW (2005) Spawning, copulation and inbreeding coefficients in marine invertebrates. Biol Lett $1: 450-453$

Ayre DJ, Miller K (2006) Random mating in the brooding coral Acropora palifera. Mar Ecol Prog Ser 307:155-160

Bishop JDD, Ryland JS (1993) Enzyme electrophoretic evidence for the prevalence of outcrossing in the hermaphroditic brooding ascidian Dendrodoa grossularia (Chordata, Urochordata). J Exp Mar Biol Ecol 168:149-165

Blanquer A (2007) Molecular markers for phylogenetic and population studies of the genus Scopalina (Porifera: Demospongiae). $\mathrm{PhD}$ dissertation, University of Barcelona

Blanquer A, Uriz MJ, Pascual M (2005) Polymorphic microsatellite loci isolated from the marine sponge Scopalina lophyropoda (Demospongiae: Halichondrida). Mol Ecol Notes 5:466-468

Blanquer A, Uriz MJ, Agell G (2008) Hidden diversity in the sympatric sponges: adjusting life-history dynamics to share substrate. Mar Ecol Prog Ser 371:109-115

Boury-Esnault N, Solé-Cava AM (2003) Recent contribution of genetics to the study of sponge systematics and biology. Boll Mus Ist Biol Univ Genova 68:3-18

Calderon I, Ortega N, Duran S, Becerro M, Pascual M, Turon X (2007) Finding the relevant scale: clonality and genetic structure in a marine invertebrate (Crambe crambe, Porifera). Mol Ecol 16:1799-1810

Carlon DB (1999) The evolution of mating systems in tropical reef corals. Trends Ecol Evol 14:491-495

Caujapé-Castells J, Baccarani-Rosas M (2005) Transformer-3: a program for the analysis of molecular population genetic data. EXEGEN Software \& Jardín Botánico Canario ‘Viera y Clavijo', Las Palmas de Gran Canaria (www.exegen.org)

Cohen S (1990) Outcrossing in field populations of two species of self-fertile ascidians. J Exp Mar Biol Ecol 140: $147-158$
Duran S, Pascual M, Estoup A, Turon X (2004) Strong population structure in the marine sponge Crambe crambe (Poecilosclerida) as revealed by microsatellite markers. Mol Ecol 13:511-522

Epperson BK (1993) Recent advances in correlation studies of spatial patterns of genetic variation. Evol Biol 27:95-155

Epperson BK (2005) Estimating dispersal from short distance spatial autocorrelation. Heredity 95:7-15

Epperson BK, Li T (1996) Measurements of genetic structure within populations using Moran's I spatial autocorrelation statistics. Proc Natl Acad Sci USA 93:10528-10532

Goudet J (1995) Fstat version 1.2: a computer program to calculate Fstatistics. J Hered 86:485-486

> Grosberg RK (1987) Limited dispersal and proximitydependent mating success in the colonial ascidian Botryllus schlosseri. Evolution 41:372-384

Gutierrez-Rodriguez C, Lasker HR (2004) Microsatellite variation reveals high levels of genetic variability and population structure in the gorgonian coral Pseudopterogorgia elisabethae across the Bahamas. Mol Ecol 13:2211-2221

> Hämmerli A, Reusch TBH (2003) Genetic neigbourhood of clone structures in eelgrass meadows quantified by spatial autocorrelation of microsatellite markers. Heredity 91: $448-455$

- Hardy OJ, Vekemans X (1999) Isolation by distance in a continuous population: reconciliation between spatial autocorrelation analysis and population genetics model. Heredity 83:145-154

> Hardy OJ, Vekemans X (2002) SPAGeDi: a versatile computer program to analyse spatial genetic structure at the individual or population levels. Mol Ecol Notes 2:618-620

Harper JL (1977) Population biology of plants. Academic Press, London

Hughes TP, Jackson JBC (1980) Do corals lie about their age? Some demographic consequences of partial mortality, fission, and fusion. Science 209:713-715

> Hunt HL, Scheibling RE (1997) Role of early post-settlement mortality in recruitment of benthic marine invertebrates. Mar Ecol Prog Ser 155:269-301

Johnson SL, Yund PO (2004) Remarkable longevity of dilute sperm in a free-spawning colonial ascidian. Biol Bull (Woods Hole) 206:144-151

Jones CS, Okamura B, Noble LR (1994) Parent and larval RAPD fingerprints reveal outcrossing in freshwater bryozoans. Mol Ecol 3:193-199

Kimura M, Crow JF (1964) The number of alleles that can be maintained in a finite population. Genetics 49:725-738

Knowlton N, Jackson JBC (1993) Inbreeding and outbreeding in marine invertebrates. In: Thornhill NW (ed) The natural history of inbreeding and outbreeding: theoretical and empirical perspectives. University of Chicago Press, Chicago, IL

Le Goff-Vitry MC, Pybus OG, Rogers D (2004) Genetic structure of the deep-sea coral Lophelia pertusa in the northeast Atlantic revealed by microsatellites and internal transcribed spacer sequences. Mol Ecol 13:537-549

> Loiselle BA, Sork VL, Nason JD, Graham C (1995) Spatial genetic structure of a tropical understory shrub. Am J Bot 82:1420-1425

Maldonado M, Uriz MJ (1999) An experimental approach to the ecological significance of microhabitat-scale movement in an encrusting sponge. Mar Ecol Prog Ser 185: $239-255$

- Mariani S, Uriz MJ, Turon X, Alcoverro T (2006) Dispersal strategies in sponge larvae: integrating the life history of larvae and the hydrologic component. Oecologia 149: $174-184$ 
McFadden CS (1997) Contributions of sexual and asexual reproduction to population structure in the clonal soft coral Alcyonium rudyi. Evolution 51:112-126

McFadden CS, Aydin KY (1996) Spatial autocorrelation analysis of small-scale genetic structure in a clonal soft coral with limited larval dispersal. Mar Biol 126:215-224

Miller K (1998) Short distance dispersal of black coral larvae: inference from spatial analysis of colony genotypes. Mar Ecol Prog Ser 163:225-233

Miller K, Ayre DJ (2008) Population structure is not a simple function of reproductive mode and larval type: insights from tropical corals. J Anim Ecol 77:713-724

Miller K, Alvarez B, Battershill C, Northcote P, Parthasarathy $H$ (2001) Genetic, morphological and chemical divergence in the sponge genus Latrunculia (Porifera: Demospongiae) from New Zealand. Mar Biol 139:235-250

Moran PAP (1948) The interpretation of statistical maps. J R Stat Soc B 37:243-251

Pascual M, Balanyà J, Latorre A, Serra L (1997) Analysis of the variability of Drosophila azteca and Drosophila athabasca populations revealed by random amplified polymorphic DNA. J Zool Syst Evol Res 35:159-164

Pemberton AJ, Hansson LJ, Craig SF, Hughes RN, Bishop JDD (2007) Microscale genetic differentiation in a sessile invertebrate with cloned larvae: investigation the role of polyembryony. Mar Biol 153:71-82

Raymound M, Rousset F (1995) GENEPOP version 1.2: population genetics software for exact tests and ecumenicism. J Hered 86:248-249

Reusch TBH, Hukriede W, Stam WT, Olsen JL (1999) Differentiation between clonal growth and limited gene flow using spatial autocorrelation of microsatellites. Heredity 83:120-126

Reusch TBH, Stam WT, Olsen JL (2000) A microsatellitebased estimation of clonal diversity and population subdivision in Zostera marina, a marine flowering plant. Mol Ecol 9:127-140

Editorial responsibility: Don Levitan, Tallahassee, Florida, USA
Schneider S, Roessli D, Excoffier L (2000) Arlequin ver. 2.000: a software for population genetics data analysis. Genetics and Biometry Laboratory, University of Geneva

Stenberg P, Lundmark M, Saura A (2003) MLGsim: a program for detecting clones using a simulation approach. Mol Ecol Notes 3:329-331

> Turon X, Tarjuelo I, Uriz MJ (1998) Growth dynamics and mortality of the encrusting sponge Crambe crambe (Poecilosclerida) in contrasting habitats: correlation with population structure and investment in defence. Funct Ecol 12:631-639

- Uriz MJ, Maldonado M, Turon X, Martí R (1998) How do reproductive output, larval behaviour, and recruitment contribute to adult spatial patterns in Mediterranean encrusting sponges? Mar Ecol Prog Ser 167:137-148

Vacelet J (1979) La place des spongiaires dans les écosystèmes trophiques marins. In: Levi $\mathrm{C}$, Boury-Esnault $\mathrm{N}$ (eds) Colloques Internationaux du CNRS: Biologie des Spongiaires. Éditions du Centre National de la Recherche Scientifique, Paris, p 259-270

Weir BS, Cockerham CC (1984) Estimating F-statistics for the analysis of population structure. Evolution 38: $1358-1370$

Whalan S, Johnson MS, Harvey E, Battershill C (2005) Mode of reproduction, recruitment, and genetic subdivision in the brooding sponge Haliclona sp. Mar Biol 146:425-433

Wulff JL (1991) Asexual fragmentation, genotype success, and population dynamics of erect branching sponges. J Exp Mar Biol Ecol 149:227-247

Yeh FC, Yang RC, Boyle TBJ, Ye ZH, Mao JX (1997) POPGENE, the user-friendly shareware for population genetic analysis. Molecular Biology and Biotechnology Centre, University of Alberta, Edmonton

Zilberberg C, Solé-Cava AM, Klautau M (2006) The extent of asexual reproduction in sponges of the genus Chondrilla (Demospongiae: Chondrosida) from the Caribbean and the Brazilian coasts. J Exp Mar Biol Ecol 336:211-220

Submitted: October 20, 2008; Accepted: January 15, 2009 Proofs received from author(s): March 23, 2009 